\title{
PIONERAS DE LA MEDICINA DEL SIGLO XIX A TRAVÉS DE SUS ESCRITOS
}

\author{
XIXTH CENTURY PIONEER MEDICAL WOMEN THROUGH THEIR WRITINGS
}

Pilar Iglesias Aparicio

\section{RESUMEN:}

Durante el último tercio del siglo XIX, las pioneras de la medicina moderna, pese a la férrea oposición al acceso de las mujeres a la educación superior y práctica profesional, fueron capaces de transmitir su conocimiento y opiniones a través de conferencias y publicaciones. Comenzaron a construir la historiografía de las mujeres médicas y matronas, divulgaron conocimientos sobre el cuidado de la salud, rebatieron el discurso misógino sobre el cuerpo y la sexualidad de las mujeres y realizaron importantes contribuciones al conocimiento científico. Este trabajo, desde el ámbito de los estudios feministas, pretende proporcionar información sobre algunas de sus obras.

\section{Palabras clave:}

Pioneras de la medicina; médicas escritoras; historiografía de médicas y comadronas; discurso científico-médico del siglo XIX.

\section{Abstract:}

During the last third of the XIXth century, pioneer female physicians, in spite of the hard opposition to women's access to higher education and professional practice, were able to transmit their knowledge and opinions, through lectures and publications. They started the historiography of women in medicine and midwifery, produced works to promote popular knowledge about health care, refuted the misogynistic discourse on women's bodies and sexuality and contributed to the construction of scientific knowledge. This paper, from the sphere of feminist studies, aims to provide information about some of their works.

\section{KEYWORDS:}

Pioneer medical women; women medical writers; historiography of medical women and midwives; XXth century scientificmedical discourse. 


\section{INTRODUCCIÓN}

Durante la segunda mitad del siglo XIX, el acceso a la educación superior y al desempeño de profesiones liberales constituyeron una reivindicación fundamental del movimiento de mujeres, junto con otras como el derecho al voto, los derechos de familia y la mejora de las condiciones laborales. La medicina fue una de las primeras especialidades universitarias a cuyo estudio intentaron acceder las mujeres en diferentes países de América y Europa. Ello constituía una ruptura de la imagen de la mujer promovida por el discurso científico-médico imperante. Un discurso que no sólo convirtió las diferencias biológicas entre mujeres y hombres en esenciales, sino que además las jerarquizó, "al describir lo propio y específico de las mujeres como inferior a lo propio y específico de los hombres y al asignar a las diferencias femeninas una positividad que sólo era tal para quienes se beneficiaban de ellas, el sistema patriarcal, pero no para las que las poseían" (Flecha, 2001, p.224). Un discurso que definía a la mujer como un ser débil, física e intelectualmente inferior al hombre, tendente a la enfermedad física y psíquica, limitado por sus funciones reproductivas, y cuyos trastornos de todo tipo se atribuían al funcionamiento de sus órganos sexuales. Un ser cuyo único destino "natural" era el matrimonio y la maternidad.

En este marco, el hecho mismo de pretender realizar estudios superiores, y concretamente estudios de medicina, con la intención de ejercer posteriormente la profesión, constituía un elemento fuertemente disruptivo de la rígida estructura patriarcal, una ruptura peligrosa del orden establecido. Consecuentemente, ante este propósito delas mujeres, la reacción delas universidades y otrasinstituciones, tales como colegios profesionales y sociedades médicas, fue extremadamente discriminatoria, legitimando su oposición con argumentos basados en la visión misógina predominante en el siglo XIX, a que acabamos de referirnos. Autores como Paul Broca ${ }^{1}$ o Carl Vogt ${ }^{2}$, defendieron la tesis de la debilidad de las mujeres basándose en el menor tamaño de su cerebro. James McGrigor Allan ${ }^{3}$ defendió la analogía entre los cerebros de las mujeres y los de los animales. También pretendió probar el inferior desarrollo del cerebro femenino el neurólogo alemán Paul Moebius en su tratado La inferioridad mental de la mujer (Über den physiologischen Schwachsinn des Weibes) de 1900. Leopold Henius", se apoyó en la debilidad muscular y ósea de las mujeres. Otros, como Hermann Fehling

1 Mémoirs d'Anthropologie (Memorias de Antropología). Paris: Reinward et Cie. Livraires-Éditeurs. Tomo I, 1871. Tomo II, 1874.

2 Lectures on Man. His place in creation, and in the history of the earth (Conferencias sobre el Hombre. Su lugar en la creación y en la historia de la tierra). Londres: Longman, 1864.

3 On the real differences in the minds of men and women (Sobre las diferencias reales en la mente de hombres y mujeres), Journal of the Anthropological Society of London, 1869.

4 Ueber die Zullasung der Frauen zum Studium der Medicin (Sobre el acceso de las mujeres al estudio de la Medicina), Deutsche medicinische Wochenschrift, 1895, pp. 612-614 
5, Edward Clark ${ }^{6}$ o Henry Maudsley ${ }^{7}$ insistieron en el carácter incapacitante de la menstruación. La misoginia de estos doctores entroncaba perfectamente con la larga tradición del pensamiento patriarcal durante siglos, al construir una visión del cuerpo, la salud y la sexualidad de las mujeres como seres débiles, enfermizos e inferiores al varón ${ }^{8}$.

Las pioneras recurrieron a diferentes estrategias para lograr acceder al estudio y práctica de la medicina moderna; muchas se vieron obligadas a recorrer un laberinto en solitario, con el apoyo, en ocasiones, de sus familias y algunos médicos de buena voluntad, como fue el caso de Elizabeth Blackwell (1821-1910) ${ }^{9}$ y Elizabeth Garrett $(1836-1917)^{10}$; otras debieron solicitar permisos especiales para poder realizar estudios superiores como las españolas Dolores Aleu Riera (1857-1913) ${ }^{11}$ y Martina Castells Ballespí (1852-1884)12; y otras, se vieron obligadas a trasladarse a países diferentes del propio, para poder estudiar u obtener titulaciones de mayor nivel, destacando las Facultades de Medicina de Berna y Zúrich, en las que se matricularon más de 100 mujeres entre 1864 y 1874, sobre todo procedentes de Rusia y Alemania (Bonner, 1992). Asimismo se organizaron colectivamente para ejercer incidencia política ante las universidades, colegios profesionales, parlamentos, gobiernos, etc. como en

5 Die Bestimmung der Frau: Ihre Stellung zu Familie und Beruf (El destino de las mujeres: Su posición en la familia y el trabajo). Sttutgart: Ferdinand Enke, 1892.

6 Sex in Education or A Fair Chance for Girls (El sexo en la Educación o Una Oportunidad Justa para las Chicas). Boston: James R. Osgood and Company,1873.

7 Sex in mind and education (El sexo en la mente y la educación), The Fortnightly Review, vol. 15, 1874.

8 Tema ampliamente desarrollado en Calvo, 2016; García Dauder y Pérez Sedeño, 2017; Iglesias, 2012 (capítulo I, II, III y IV), y 2020; Moscucci, 1990 y Russet, 1995.

9 Médica estadounidense de origen británico, primera mujer Graduada en Medicina en EEUU por una escuela oficial: la Escuela de Medicina de Geneva (estado de Nueva York), en 1849. Primera mujer que accedió al Registro Médico de Gran Bretaña en 1859. Fundadora en 1857 del Hospital de Mujeres y Niños de Nueva York (New York's Infirmary for Women and Children) y en 1868 de la Escuela de Medicina de Mujeres de dicho Hospital.

10 Primera mujer que obtuvo la Licencia de la Sociedad de Boticarios (Society of Apothecaries) en 1865; segunda en acceder al Registro Médico de Gran Bretaña, en 1866; primera Doctora en Medicina por la Soborna de París el 15 de junio de 1870 y segunda Doctora en Medicina británica, tras Francis Hoggan; cofundadora de la Escuela de Medicina de Mujeres de Londres en 1874, y decana de la misma desde 1883 hasta 1902. En 1866, puso en marcha un dispensario para mujeres, que se convirtió en 1872 en el Nuevo Hospital para Mujeres (New Hospital for Women) de Londres, en funcionamiento hasta finales del siglo XX. Primera mujer cirujana de Gran Bretaña y primera en realizar ovariotomías y otras cirugías abdominales. En 1874, fue también la primera mujer en acceder a la Asociación Médica Británica (British Medical Association). Ver: Crawford, 2006; Iglesias, 2012 y 2018b.

11 Primera Doctora en Medicina de España. Presentó su tesis doctoral en la Facultad de Medicina de Madrid, única donde se podía acceder al Doctorado, el 6 de octubre de 1882.

12 Segunda Doctora en Medicina de España. Presentó su tesis doctoral el 9 de octubre de 1882. 
elcaso de Sophia Jex-Blake (1840-1912 $)^{13}$ y sus compañeras frente a la Universidad de Edimburgo (Jex-Blake, 1886, Vol. II; Iglesias, 2018a, p.233), o el movimiento social de apoyo a las médicas alemanas (Bonner, 1992, p.111); crearon escuelas de medicina de mujeres, como en el caso de Nueva York, Londres, Edimburgo y Glasgow; establecieron hospitales para mujeres atendidos únicamente por mujeres; fundaron asociaciones de mujeres médicas y tomaron la palabra para rebatir los argumentos discriminatorios esgrimidos por sus opositores ${ }^{14}$.

Los países que contaron con mayor número de médicas a lo largo del último tercio del siglo XIX fueron Estados Unidos y Gran Bretaña, debido, fundamentalmente a las escuelas de medicina de mujeres. Entre 1850 y 1882, se crearon escuelas de este tipo en las principales ciudades estadounidenses: Boston, Nueva York, Filadelfia, Chicago, y Baltimore. En Gran Bretaña existieron cuatro, una en Londres (la London School of Medicine for Women, en adelante la Escuela o LSMW, por sus siglas en inglés), dos en Edimburgo y una en Glasgow: el Departamento de Medicina de la Universidad Reina Margarita (Queen Margaret College), dedicado exclusivamente a la educación de las mujeres (Iglesias, 2018a, p.234).

Muchas de las médicas pioneras produjeron una importante obra escrita a través de la publicación de conferencias, tesis doctorales, artículos, investigaciones, libros, y, en el caso de la LSMW a través del Magazine donde también participaban las alumnas. Podemos clasificar estas obras de acuerdo con sus principales temáticas: contribución a la historiografía de las mujeres en el cuidado de la salud; defensa de la capacidad de las mujeres para el estudio y práctica de la medicina; aportación de argumentos científicos para deconstruir la misoginia del discurso médico dominante; producción de obras de divulgación sobre salud sexual de las mujeres, cuidado de la salud infantil y normas de higiene; así como publicación de obras de carácter científico sobre diferentes temas. Y todo ello, pese a la dificultad añadida de no permitírseles el acceso a los espacios de creación y puesta en común del conocimiento científico-médico, como las diferentes asociaciones y colegios profesionales. El interés por las publicaciones de las pioneras continúa dando lugar a estudios como el publicado por Susan Wells en 2001, centrado

13 Doctora en Medicina por la Universidad de Berna en enero de 1877 y Licenciada por el Colegio Médico de Irlanda en marzo de ese mismo año para poder acceder al Registro Médico de Gran Bretaña, que no reconocía titulaciones obtenidas en el extranjero, siendo la quinta mujer en acceder a dicho registro. Convirtió la reivindicación del acceso de las mujeres al estudio y práctica de la medicina en causa social, siendo figura fundamental en las acciones ante el trato discriminatorio dispensado a ella y sus compañeras por la Universidad de Edimburgo. En 1874, promovió la fundación de la Escuela de Medicina de Mujeres de Londres. Ejerció como médica en Edimburgo desde 1883, donde fundó un Hospital para Mujeres y una Escuela de Medicina de Mujeres.

14 Sobre las diferentes dificultades y estrategias, ver: Bonner, 1996; Flecha, 1996 y 2019; Flecha y Palerno, 2019 e Iglesias, 2012, 2018a y 2019. 
en Ana Preston (1813-1872) ${ }^{15}$; Hannah Longshore (1819-1901) ${ }^{16}$, Rebecca Crumpler $(1831-1895)^{17}$ y Mary Putnam Jacobi (1840-1906) ${ }^{18}$, o la obra de Carla Bittel sobre Mary Putnam, publicada en 2009, en que brinda amplia información sobre las investigaciones realizadas por esta doctora. El presente trabajo pretende visibilizar algunas de estas aportaciones de las pioneras de la medicina moderna a través de sus escritos.

\section{Aportaciones a la historiografía de las mujeres en el CUIDAdo de LA SALUD Y DEFENSA DE LA CAPACIDAD DE LAS MUJERES PARA EL ESTUDIO Y EJERCICIO DE LA MEDICINA}

Varias pioneras realizaron una importante aportación a la construcción de la historia de las mujeres en el cuidado de la salud. Demostrar la existencia de una genealogía de médicas y matronas en épocas anteriores, contribuía a fortalecer y legitimar su posición y a rebatir los argumentos esgrimidos contra ellas. Además, algunas autoras se convirtieron en las primeras historiadoras de su propio proceso, con lo que sus obras constituyen una magnífica fuente de detallada información para toda investigación posterior sobre las dificultades que hallaron para acceder a la universidad, las acciones de incidencia social y política emprendidas, los procesos de creación de escuelas de medicina de mujeres, etc. Estas obras sirvieron también en su momento para obtener apoyo social, y en ocasiones económico, para sus proyectos.

Podemos afirmar con Teresa Ortiz (2018), que "la historiografía de las mujeres, la medicina y la salud (HMMS) se comenzó a escribir al mismo tiempo que las mujeres empezaron a acceder a la profesión médica en el último tercio del siglo XIX" (pp.6586). Como recoge dicha autora: “Entre 1872 y 1901 se publicaron alrededor de una docena de trabajos sobre la historia de las mujeres en la profesión médica, firmados en su mayoría por profesionales de la medicina" (Ortiz, 2018, pp.86-87), además de numerosas autobiografías o memorias.

15 Graduada en Medicina por la Female Medical College of Pennsylvania (Escuela de Medicina de Mujeres de Pensilvania), en 1851, de la que fue decana entre 1866 y 1872.

16 Graduada en 1851 por esta misma Escuela. Profesora de Anatomía en la Universidad de Medicina de Pensilvania entre 1853 y 1857.

17 Trabajó como enfermera mientras realizaba sus estudios de medicina. Doctora en Medicina por la New England Female Medical College (Escuela de Medicina de Mujeres de Nueva Inglaterra) en 1864, siendo la primera médica afroamericana de los EEUU.

18 Mary Corinna Putnam, conocida como Mary Putnam Jacobi, por el apellido de su esposo, el también Doctor en Medicina Abraham Jacobi, con el que colaboró ampliamente a nivel profesional. Graduada en Farmacia por la Facultad de Farmacia de Nueva York en 1863 y en Medicina por la Escuela de Medicina de Mujeres de Pensilvania en 1864. Segunda mujer que obtuvo el Doctorado en Medicina por la Sorbona de París en 1871. Primera mujer admitida en la Academia de Medicina de Nueva York, en 1880, cuya cátedra de neurología presidió. Publicó más de ciento veinte artículos y nueve libros. Ver: Bittel, 2009; Iglesias, 2018b y 2020. 
Sophia Jex-Blake es la primera médica ${ }^{19}$ que publica, en $1872^{20}$, un libro sobre la historia de las mujeres en el cuidado de la salud. El primer volumen de su obra Medical Women. A thesis and a history (Mujeres médicas. Una tesis y una historia) se centra en la historia de mujeres médicas y comadronas. Jex-Blake afirma que las mujeres "están naturalmente inclinadas y provistas de características adecuadas para la práctica de la medicina" (1886, p.6) ${ }^{21}$ pero que nadie tiene derecho a determinar que "no se les permita hacer su trabajo de forma científica cuando lo deseen y queden limitadas a los detalles mecánicos y la rutina agotadora de la enfermería, mientras se reserva para los hombres el conocimiento inteligente de la enfermedad y todo el estudio de las leyes por las que se preserva o restituye la salud" (Jex-Blake, 1886, p.6). Este será un argumento esgrimido con frecuencia por las pioneras: si se atribuye a las mujeres el cuidado de la salud en el ámbito doméstico y en el duro trabajo de enfermería, no se justifica la negativa a su acceso al conocimiento científico, la obtención de titulaciones y el acceso a la práctica profesional en igualdad con los varones. Defiende asimismo JexBlake como algo natural que hombres y mujeres se dediquen a atender la salud de las personas de su propio sexo, sin suponer por ello que sea moralmente reprobable que las mujeres sean atendidas por varones. Su recorrido histórico comienza en la Grecia clásica, incluye numerosas referencias a matronas, para llegar a su época y reforzar sus argumentos con la experiencia adquirida durante su estancia en Estados Unidos ${ }^{22}$ y en la Universidad de Berna.

La segunda médica que publicó un libro sobre las mujeres en la historia de la medicina, fue Mélanie Lipinska (1865-1933), cuya tesis doctoral, presentada ante la Facultad de Medicina de la Universidad de París el 18 de julio de 1900, fue publicada con el título Histoire des femmes médecins depuis l'Antiquité jusqu'à nos jours (Historia de las

19 En 1875, el médico francés Gustave Richelot (1806-1893), publicó su obra Les femmes médecins (Las mujeres médicas). El segundo autor que publicó un libro sobre la historia de las mujeres en el cuidado de la salud fue Marcel Baudouin (1860-1901). Recopiló abundantes datos bibliográficos sobre médicas del pasado con el objeto de apoyar la causa de las médicas de su tiempo, y publicó su obra, Les femmes médecins. Étude de psychologie sociale internationale. Tome I. Femmes médecins d'autrefois. (Las mujeres médicas. Estudio de psicología internacional. Tomo I. Mujeres médicas del pasado), en 1899 para conmemorar el cincuentenario de la graduación de Elizabeth Blackwell (Ortiz, 2018, p.94).

20 La primera edición es, efectivamente, de 1872, como queda constancia por los comentarios publicados en el Evening Standard de 19 de noviembre de dicho año, incluidos en la segunda edición, de 1886, que es la única accesible.

21 Todas las traducciones de originales en inglés son de la autora.

22 En 1865, Sophia-Jex Blake residió y desempeñó tareas administrativas en el New England Hospital for Women (Hospital de Mujeres de Nueva Inglaterra), invitada por su amiga, la médica estadounidense Lucy Sewall. Allí descubrió su vocación por la medicina y en 1866 se matriculó en la Escuela de Medicina de Mujeres de Nueva Inglaterra (New England Female Medical College). Dada la baja calidad de las clases, intentó acceder a la Universidad de Harvard y ante la negativa, se incorporó al Hospital de Mujeres y Niños de Nueva York (New York's Infirmary for Women and Children) fundado por las hermanas Elizabeth y Emily Blackwell, y en 1868 se matriculó en la recién creada Escuela de Medicina de Mujeres del Hospital de Nueva York (Women's Medical College of the New York's Infirmary for Women and Children). Ver Iglesias, 2012, 2018b y 2019. 
mujeres médicas desde la Antigüedad hasta nuestros días), obra por la que recibió el premio literario Víctor Hugo en 1902. Se trata de un trabajo de 584 páginas, mucho más amplio que el de Jex-Blake, que recorre desde la Antigüedad hasta 1900, proporcionando información sobre "matronas, sanadoras, enfermeras y religiosas, combinando el relato biográfico personal con los estados de la cuestión por épocas, países, escuelas o actividades profesionales" (Ortiz, 2018, p.92). Incluye "una amplísima bibliografía multilingüe donde las referencias a fuentes escritas por mujeres (libros de partos, de enfermería, memorias de médicas pioneras o ensayos políticos) son muy numerosas" (Ortiz, 2018, p.92). En su segunda obra, publicada ya en 1930, dedica más de la mitad de sus 220 páginas a la situación de las médicas en los siglos XIX y XX.

Tras Jex-Blake y Mélanie Lipinska, la siguiente médica que contribuyó con un libro a la historiografía de las mujeres en el cuidado de la salud fue Kate Campbell HurdMead, con su obra de 523 páginas, titulada Women in Medicine. From the earliest times to the beginning of the nineteenth century (Las Mujeres en la Medicina. Desde los primeros tiempos hasta el comienzo del siglo diecinueve) publicada en 1939.

El segundo volumen de la obra de Jex-Blake, titulado, The Medical Education of Women: 1. The Battle in Edinburgh, 2. The Victory Won (La Educación médica de las Mujeres:

\section{La Batalla en Edimburgo. 2. La Victoria conseguida),}

resulta una magnífica fuente de información sobre los hechos acaecidos en la Universidad de Edimburgo entre 1869 y 1874, sobre los requisitos impuestos por la Ley de 1858 para acceder al Registro, y las circunstancias que provocaron que la creación de una escuela de medicina para mujeres fuese imprescindible para facilitarles el acceso al estudio y práctica de la medicina en Gran Bretaña. Además, al incluir como anexo la transcripción de numerosos documentos, su obra ofrece a quien quiera llevar a cabo una investigación sobre la propia Jex-Blake y la lucha de las mujeres por acceder a la Universidad de Edimburgo, la práctica totalidad de los documentos relevantes (Iglesias, 2018b, p.7).

También publicó Jex-Blake los ensayos The practice of medicine by women (La práctica de la medicina por las mujeres), en 1875 y Medical women (Mujeres médicas) en 1877.

Francis Hoggan ${ }^{23}$ publicó en 1884 el capítulo titulado Women in Medicine (Mujeres en la Medicina), en la obra colectiva editada por Theodore Stanton, The Woman question in Europe (La Cuestión de la Mujer en Europa)24. Hoggan dedica varias páginas a Elizabeth

23 Francis Elizabeth Morgan (1843-1927), conocida por el apellido de su esposo, el también doctor en medicina Georges Hoggan. Primera mujer británica Doctora en Medicina, al obtener el Doctorado en la Universidad de Zúrich, en marzo de 1870. Colaboró con Elizabeth Garrett en el Nuevo Hospital de Mujeres de Londres. En colaboración con Georges Hoggan publicó más de cuarenta estudios en inglés, alemán y francés. Entre otros, su investigación sobre la anatomía y la fisiología de los ganglios linfáticos.

24 Obra sobre la situación de las mujeres en Europa, que dedica cinco apartados a Inglaterra: movimiento feminista, movimiento para la educación de las mujeres, movimiento industrial, las mujeres como filántropas y las mujeres en la medicina; dos a Alemania: movimiento de mujeres y 
Blackwell, Elizabeth Garrett, la Escuela de Medicina de Mujeres de Londres, y la modificación que supuso la conocida como "Ley Russell Gurney", aprobada en el Parlamento en 1876, que concedió a los Tribunales Examinadores la capacidad de decisión para admitir mujeres, lo que permitió que dos universidades de Irlanda, el King and Queen's College of Physicians (Colegio Médico del Rey y la Reina) y la Queen's University (Universidad de la Reina), fuesen las primeras en permitir acceder a sus exámenes a las mujeres, siendo seguidas por la Universidad de Londres en 1877. Hoggan refiere su propia experiencia al verse obligada a matricularse en la Universidad de Zúrich, tras modificar en 1867 sus estatutos la Sociedad de Boticarios, exigiendo que quienes se presentasen a sus exámenes hubiesen cursado estudios en una facultad o escuela reconocida y no mediante clases particulares con doctores (como había sido el caso de Elizabeth Garrett). Esta decisión tenía como propósito y consecuencia impedir el acceso de las mujeres a los exámenes de la Sociedad, puesto que no se les permitía matricularse en ninguna de las escuelas o facultades existentes en Gran Bretaña.

Incluye cinco páginas redactadas por su esposo, el Dr. Hoggan, sobre el tratamiento recibido por las mujeres que intentaron acceder a la Facultad de Medicina de la Universidad de Edimburgo entre 1869 y 1872, en el que este elabora un relato que, en cierto modo, disculpa el comportamiento de la universidad y critica a quien lideraba el grupo de mujeres (Sophia Jex-Blake), sin mencionarla directamente. Manifiesta la autora que la opinión pública en Inglaterra "en la cuestión de las mujeres médicas, está por delante de la opinión general de la profesión médica, pese a la generosa ayuda que algunos miembros de esta profesión han dispensado siempre a sus hermanas profesionales, a menudo con gran detrimento personal propio" (Hoggan, 1884, p.88); y concluye refiriéndose al incremento de mujeres médicas en Inglaterra; la existencia de dispensarios atendidos por mujeres en Londres, Bristol y Manchester; las médicas misioneras en la India y la forma en que "las mujeres están comenzando a también a contribuir a la literatura médica y la investigación científica" (Hoggan, 1884, p.88).

También en 1884, coincidiendo con el décimo aniversario de su fundación, la LSMW convocó un concurso de ensayos sobre la práctica médica por las mujeres, abierto a la participación de estudiantes y graduadas. La ganadora fue la entonces alumna de segundo curso, Edith A. Huntley (1852-1917) ${ }^{25}$. Su trabajo, titulado The Study and Practice of Medicine by Women (El Estudio y Práctica de la Medicina por las Mujeres) fue publicado

asociación nacional de mujeres alemanas y dos a Italia, una visión general y el movimiento por la educación, y uno a cada uno de los siguientes países: Holanda, Austria, Noruega, Suecia, Dinamarca, Francia, España (del que fue autora Concepción Arenal), Portugal, Bélgica, Suiza, Rusia, Polonia y Bohemia más un capítulo sobre El Oriente.

25 Huntley había obtenido asimismo una beca de 30 libras en su examen obligatorio de ingreso a la Escuela en 1882, como recoge el Illustrated London News de ese año. Se graduó en la Universidad de Edimburgo en 1887. Ejerció la medicina en la India hasta 1902, y posteriormente en Wellington (Nueva Zelanda) donde residió hasta su fallecimiento. 
en 1886. Huntley rebate los argumentos esgrimidos por quienes se oponían al ejercicio de la medicina por las mujeres, defendiendo su capacidad intelectual, probada por los excelentes resultados obtenidos en los exámenes realizados ante los Tribunales Examinadores de Dublín y Londres; hace referencia a la historia de las mujeres en el cuidado de la salud desde la Antigüedad y se extiende en el proceso de aprobación de la Ley Russell, la apertura de los exámenes de la Universidad de Londres y la historia de la $L S M W$. Dedica varias páginas a las matronas y propone que "se debería establecer en Inglaterra una Escuela de Matronas digna de una de las naciones más adelantadas del mundo, y retirar de la medicina obstétrica inglesa el reproche de que sus mejores estudiantes deben completar su formación en París o Viena" (Huntley, 1886, p.39). Se refiere al papel que pueden desempeñar las mujeres médicas como misioneras, e incluso como cirujanas, destacando siempre la importancia de que cuenten con una buena formación teórica y práctica. Aunque reitera la consideración habitual en su tiempo, de que las médicas deben dedicarse principalmente a la atención de mujeres y niñas y niños, afirma que no deben de existir restricciones para optar por otras especialidades.

En 1882, Mary Putnam publicó en la North American Review un artículo de 23 páginas, titulado Shall Women practice Medicine? (¿Deben las Mujeres practicar la Medicina?), que comienza criticando el hecho de que la capacidad de las mujeres sea objeto de debate social mientras no lo es la de los hombres. En 1891, publicó un trabajo de 96 páginas, titulado Woman in Medicine (La Mujer en la Medicina), en el libro colectivo editado por Annie Nathan Meyer (1867-1951), Woman's work in America (El trabajo de la mujer en América). Putnam "establece siete momentos en la historia de las médicas en Estados Unidos desde el periodo colonial hasta sus días, y dedica la mayor parte del texto a la historia reciente de la formación de las médicas en instituciones femeninas, creadas exclusivamente para ellas" (Ortiz, 2018, p.91). Constituye una brillante aportación a la historia de las mujeres en la medicina, citada con frecuencia (Ortiz, 2018, p.91).

Entre los numerosos artículos publicados por Elizabeth Garrett, destacamos en este apartado el publicado en marzo de 1893 en la Fortnightly Review, con el título The history of a movement (La historia de un movimiento). Comienza recordando que el movimiento de mujeres médicas se inició a partir de la idea de que "sería adecuado que el cuidado de la salud de mujeres y niños fuese atendido por mujeres profesionales" (Garrett, 1893, p.404) ${ }^{26}$. Además de las referencias a Elizabeth Blackwell, Sophia JexBlake, ella misma y la creación de la LSMW, ofrece algunos datos interesantes sobre la

26 Elizabeth Garrett, al igual que muchas otras pioneras, mantuvo durante toda su vida profesional la decisión de atender únicamente a mujeres, rechazando siempre a los pacientes varones. En otros muchos casos, esta era la única práctica profesional que les estaba permitida a las mujeres. Con el paso del tiempo, muchas médicas defendieron el derecho a acceder a todas las especialidades y a poder atender, igual que sus colegas varones, a hombres y mujeres. 
evolución de la situación en los 16 años transcurridos desde 1877 hasta 1893, fecha en que admitían mujeres seis Tribunales Examinadores ${ }^{27}$ y ocho escuelas de medicina: las cuatro específicas para mujeres de Londres, Edimburgo y Glasgow, y cuatro mixtas, una en Durham y tres en Irlanda (Dublín, Belfast y Cork). La importancia de las escuelas solo para mujeres queda demostrada en el hecho de que cursaban en ellas 240 estudiantes, mientras solo lo hacían 17 en las mixtas (Garrett, 1893, p.408). Este fue uno de los temas de debate planteados con frecuencia, puesto que no todas las pioneras coincidían en qué tipo de enseñanza (mixta o específica) podía ser más conveniente para las futuras médicas. Garrett considera que no es momento de pronunciarse sobre este extremo, pero sí establece tres consideraciones a tener en cuenta como orientación para las jóvenes que deseen estudiar medicina: la necesidad de una formación teórica y práctica de calidad; el tipo de centro que se adapte mejor a las características de la estudiante, teniendo en cuenta que las más jóvenes pueden sentirse más cómodas en las escuelas específicas; y, por último, el gasto que su familia pueda permitirse, puesto que existían importantes diferencias en el coste de las diferentes instituciones académicas, aspecto sobre el que también ofrece información. Lamenta que no todas las universidades brinden las mismas titulaciones, y señala la dificultad que representa para una escuela pequeña como la $L S M W$, preparar a las estudiantes para los exámenes de la Universidad de Londres, dado los gastos requeridos, razón por la que la mayoría de personas que obtenían este preciado Doctorado en Medicina procedían de las escuelas de los grandes hospitales y la propia Universidad de Londres (Garrett, 1893, p.412), que no admitían mujeres. Continúa el artículo refiriéndose a las salidas profesionales para las médicas, destacando en primer lugar los centros atendidos únicamente por mujeres: el Nuevo Hospital para Mujeres, trasladado desde 1889 a Euston Road, la Maternidad Clapham, fundada en 1885 por una antigua alumna de la Escuela, y el dispensario de Notting Hill. En el momento de publicación del artículo se habían incorporado al Registro Médico, 144 mujeres, de las cuales 45 ejercían en Londres. Habían comenzado a crearse puestos públicos en hospitales infantiles, y para la atención de las empleadas de Correos, en Londres, Manchester y Liverpool. Otra salida profesional era ejercer en las colonias: India, China, Sudáfrica y Australia. En este caso, las médicas deben saber que "su ayuda se solicitará sólo para casos médicos graves, operaciones ginecológicas o de cirugía general que requieran el mayor nivel de pericia, coraje y experiencia" (Garrett, 1893, p.415). No carente del racismo y clasismo imperante en la época, insiste en las dificultades que presenta para una dama inglesa residir en la India y recomienda que sean las propias mujeres nativas quienes se formen para ejercer como médicas en el país, añadiendo el matiz interesante de que "las mujeres de la India serían las más beneficiadas y, a largo plazo, se podría

27 Las Universidades de Londres, Irlanda y Glasgow, la Sociedad de Boticarios denominada ahora Apothecaries'Hall, los Colegios de Médicos y Cirujanos de Edimburgo y Glasgow y los de Dublín. 
esperar mucho más de una influencia de este tipo, que comenzaría desde dentro de la propia sociedad de la India, en vez de intentar influir desde fuera, que del sacrificio, aunque sea heroico y desinteresado, de unas pocas mujeres europeas" (Garret, 1893, p.416). Por último, lamenta Garrett que las mujeres sigan estando excluidas de todas las sociedades médicas de Londres, siendo ella la única admitida en la Asociación Médica Británica desde 1872, aunque varias de las secciones de otras ciudades habían comenzado ya a proponer su apertura a las mujeres (p.416). Finaliza recordando que las médicas podían utilizar la excelente biblioteca provista de las principales publicaciones británicas y estadounidenses y la sala de conferencias del Nuevo Hospital de Mujeres, donde se celebraban sesiones mensuales de presentación de ponencias debatidas por las componentes de la Association of Registered Medical Women (Asociación de Mujeres Médicas Registradas) $)^{28}$ (Garrett, 1893, p.417).

En 1895, Elizabeth Blackwell publicó una obra autobiográfica, de 265 páginas, titulada, Pioneeer work: Autobiographical sketches (Trabajo pionero: sketches autobiográficos), en que recoge las dificultades encontradas hasta acceder a la Escuela de Medicina de Geneva, su estancia posterior en La Maternité de París, la fundación del Hospital de Mujeres de Nueva York y posteriormente de la correspondiente Escuela de Medicina de Mujeres del Hospital junto con su hermana Emily, y su regreso definitivo a Londres en 1874, coincidiendo con la apertura de la $L S M W$, en la que aceptó ser profesora de Ginecología.

El 25 de enero de 1898, Mary Scharlieb (1845-1930) ${ }^{29}$ pronunció una conferencia en el Women's Institute (Instituto de las Mujeres) de Londres, de la que éste publicó una tirada reducida de ejemplares. Apelando a la genealogía de mujeres sanadoras, inicia su exposición con estas palabras: “Desde los tiempos más remotos de que tenemos noticia, desde los días de Moisés, las mujeres han practicado la medicina en mayor o menor medida. La idea de que es demasiado arduo o de que el estudio y práctica de la profesión es desmoralizador para las mujeres es completamente moderna" (Scharlieb, 1898, p.3). Brinda información que nos permite apreciar algunos avances: en los cinco años transcurridos desde el artículo de Garrett, el número de mujeres médicas incluidas en el Registro había ascendido a más de 200, la Escuela contaba con 170 alumnas y dos sociedades médicas, la Asociación Médica Británica y la Sociedad de Anestesistas (Society of Anaesthetists), admitían ya mujeres (Scharlieb, 1898, p.14). También habían aumentado los hospitales y dispensarios atendidos por mujeres. Completan esta

28 La creación de asociaciones de mujeres médicas fue una de las estrategias a que recurrieron las pioneras en Gran Bretaña y Estados Unidos. La Asociación de Mujeres Médicas Registradas había sido constituida en 1879, teniendo como secretaria honoraria a la médica escocesa Eliza Walker Dunbar (1845-1925) (Crawford, 2002, p.108).

29 Graduada en Medicina por la Universidad de Madrás (India). Completó su formación en la LSMW y se graduó en la Universidad de Londres en 1882. Ejerció como cirujana en el Nuevo Hospital para Mujeres de Londres 
publicación cuatro apéndices con información sobre: escuelas de medicina abiertas a las mujeres; titulaciones a que podían optar; puestos de trabajo oficiales abiertos a las mujeres y una bibliografía sobre educación y práctica de las mujeres médicas que incluye tres publicaciones en alemán y una en francés.

Isabel Thorne (1834-1910) ${ }^{30}$, contribuyó a la historia de las pioneras en Gran Bretaña con algunos artículos publicados en el Magazine de la LSMW, a partir de mayo de 1896.

Profunda conocedora de la historia de la $L S M W$, a la que dedicó su vida profesional, publicó en 1905 una obra de 45 páginas, titulada Sketch of the Foundation and Development of the London School of Medicine for Women (Sketch de la Fundación y Desarrollo de la Escuela de Medicina de Mujeres de Londres), contribuyendo así a la historia de la misma. En primer lugar, hace referencia a las dificultades encontradas por ella para acceder a los estudios de medicina, lo que provocó su decisión de trasladarse a París en 1869. Pero, tras conocer a Sophia Jex-Blake, se unió a ella y otras jóvenes que tenían el mismo propósito, para intentar ser admitidas en la Universidad de Edimburgo. Thorne dedica 14 páginas a referir los diferentes obstáculos que impidieron la graduación de las estudiantes por la Universidad de Edimburgo, pese a haber logrado completar la formación requerida, a fin que "quede constancia de las condiciones bajo las que comenzó la Escuela, de manera que las estudiantes puedan saber a quién deben la fundación de la que puede justamente ser considerada la Escuela Madre de todas las Escuelas de Medicina de Mujeres de Gran Bretaña" (Thorne, 1905, p.19), en claro homenaje a Sophia Jex-Blake.

Completa su historia de la LSMW con una referencia a las cualidades de una buena médica:

debería ser sabia y empática, con una mente clara y lógica, mucho sentido común, buen juicio, tacto y comprensión de la naturaleza humana, capaz de inspirar confianza a sus pacientes. Entra en contacto con tantas criaturas humanas, tiene una experiencia tan variada de situaciones difíciles, que requiere no solo un profundo conocimiento de medicina y cirugía, sino también de los principios subyacentes y la capacidad de aplicar su conocimiento de la manera más recomendable en cada caso. Debe de ser generosa con gran capacidad para aceptar las dificultades. Si opta por la cirugía requerirá gran habilidad práctica [...] Debe de ser capaz de enfrentar responsabilidades, puesto que la vida y la muerte están a menudo en sus manos y mucho depende su juicio; la buena salud también es una condición muy importante. [...] Su profesión le brinda una esfera de acción en que puede ejercer las más altas cualidades. Confiamos en las generaciones de estudiantes de Medicina presentes y futuras para que justifiquen la dura batalla de las pioneras del movimiento y muestren su aprecio de los esfuerzos realizados para asegurar que las mujeres gocen de libertad para acceder a la formación y poder dispensar tratamiento médico y quirúrgico a su propio sexo (Thorne, 1905, p.45).

30 Formó parte del grupo de pioneras que intentaron acceder a la Facultad de Medicina de la Universidad de Edimburgo. Participó en la fundación de la LSMW, y renunció a completar sus estudios para dedicarse a ser secretaria de la misma desde 1877 a 1908. 
También Franziska Tiburtius (1843-1927) ${ }^{31}$ y otras pioneras alemanas escribieron sobre la historia de su lucha por la obtención de títulos universitarios y las dificultades que encontraron en la práctica médica, y publicaron libros divulgativos de medicina doméstica (Meyer, 2001, pp.251-276). La reformadora social Mathilde Weber (18191901), en su libro titulado Mujeres Médicas para Enfermedades de las Mujeres: Una Necesidad Ética y Sanitaria, publicado en 1888, defendía la necesidad de que se formasen médicas en Alemania "para poder evitar que miles de mujeres, que evitaban visitar a un doctor por sentimientos de vergüenza o delicadeza, pudiesen preservar su pudor" (Bonner, 1996, p.112). ${ }^{32}$ También algunos médicos alemanes defendieron la capacidad de las médicas en sus escritos (Bonner, 1992, p.110).

\section{Obras de CARÁCTER PEDAgógICO Y ORIENTACIONES DIRIGIDAS A LAS ESTUDIANTES}

Florence Nightingale (1820-1910) ${ }^{33}$, publicó Notes on Nursing (Notas sobre Enfermería) en 1859, tres años después de su regreso de la Guerra de Crimea, tras haber publicado el año anterior una obra sobre las condiciones de los hospitales del ejército británico. Aunque tan solo seis meses más tarde, ya en 1860, fundaría la Nightingale Training School of Nurses of St Thomas's Hospital (Escuela de Enfermeras Nightingale del Hospital de Santo Tomás), no era su intención producir un manual de estudio para futuras enfermeras. En el prefacio afirma "Las siguientes notas no pretenden ser un conjunto de normas que las enfermeras puedan utilizar para aprender a cuidar, y mucho menos un manual para enseñar a las enfermeras a cuidar. Simplemente pretenden dar algunas pistas a todas las mujeres que tengan a su cuidado la salud de otras personas" (Nightingale, edición de 1969, p.3), dando por descontado que el cuidado de la salud es misión de todas las mujeres en un momento u otro de sus vidas. Pese a ello, se considera la primera obra escrita que contribuyó a la modernización y profesionalización de la enfermería, proporcionando información práctica sobre higiene, ventilación, iluminación, niveles de ruido, alimentación, limpieza, condiciones de la cama para la persona enferma, observación de pacientes, etc.

31 Emily Lehmus y Franziska Tiburtius fueron las dos primeras mujeres alemanas graduadas en Medicina en Zurich en 1876. Tras titularse, pese a las múltiples barreras contra las médicas existentes en su país y el acoso que sufrieron por parte de algunos de sus colegas varones, lograron instalar una clínica para mujeres pobres en Berlín.

32 El argumento del pudor era utilizado tanto por los detractores de las mujeres médicas como por quienes apoyaban su causa.

33 Considerada pionera en la reforma de la enfermería, aunque habían existido otras iniciativas como la Training Institution for Nursing Sisters (Institución de Formación para Enfermeras), fundada en 1840 por la reformadora social Elizabeth Fry; la creación de St John's House en 1848, y los avances introducidos por la enfermera jefa del Hospital de Santo Tomás, Sarah Wardroper, a partir de 1854 (Iglesias, 2012, pp.235-243). 
Elizabeth Garrett creó un cuaderno de trabajo que pretendía brindar a las alumnas de la Escuela un instrumento donde poder anotar todo su trabajo clínico para referencia posterior. Garrett nunca publicó el contenido de sus clases, pero los apuntes elaborados por su alumna Louisa Aldrich-Blake (1865-1925) ${ }^{34}$ se conservan y pueden ser consultados en la biblioteca de la Fundación Wellcome de Londres.

Los consejos y orientaciones a las jóvenes interesadas en acceder a la profesión médica constituyen el objeto de diferentes artículos y conferencias de las médicas pioneras, en ocasiones con motivo de la inauguración del curso académico, como la pronunciada por Marie Zakrzewska (1829-1902) ${ }^{35}$ el 2 de noviembre de 1859, en la Escuela de Medicina de Mujeres de Nueva Inglaterra, recién nombrada profesora de la misma, o la pronunciada por Mary Scharlieb en la inauguración del curso de la LSMW de 1887, publicada en 1888, con el título de Seven lamps of Medicine (Siete lámparas de la Medicina). Jugando con el título de la obra publicada en 1849 por el crítico de arte John Ruskin, Scharlieb considera que el camino a recorrer por las estudiantes de medicina tiene que estar iluminado por una potente luz, compuesta por siete rayos. Muestra así, los valores en que la Escuela pretendía educar a las estudiantes: Obediencia, Autoexigencia, Sinceridad, Coraje, Amabilidad, Humildad y Sacrificio. Demanda de las alumnas una entrega en el altar de la profesión médica (p.21), en nombre de la devoción que deben a las pioneras que las han precedido. Pese al tono excesivamente moralizante de la conferencia, ésta encierra algunos consejos útiles: "Entre todas las falacias y apariencias que debemos evitar están las de parecer que hacemos lo que no estamos haciendo o que sabemos lo que ignoramos" (Scharlieb, 1888, p.12), consejo que seguramente deberían haber escuchado muchos médicos de la época. "Nunca tengáis miedo de decir «no sé». Ningún ser humano puede saberlo todo" (Scharlieb, 1888, p.13). “Tenemos que ser capaces de dejar de lado nuestras propias ansiedades, fatigas e incluso la enfermedad, para tratar a nuestras pacientes con una inteligencia siempre activa y una apreciación certera de su situación" (Scharlieb, 1888, p.17). Y está siempre presente la preocupación de la Escuela por exigir a sus alumnas un alto nivel de trabajo para adquirir la mejor formación posible, que deberá continuar tras la graduación “Es innecesario recordaros que obtener una titulación, lejos de marcar el

34 Licenciada en Medicina y Máster en Cirugía por la Universidad de Londres. Decana de la LSMW desde 1914 hasta su muerte en 1925. Fue la primera mujer nombrada cirujana en el Royal Free Hospital, donde también ejerció como anestesista. Se incorporó al grupo de médicas militares durante la Primera Guerra Mundial. Es la única médica pionera que cuenta con un monumento en Londres, en Tavistock Square.

35 Médica de origen polaco. Se formó como comadrona en Berlín, y posteriormente se trasladó a Estados Unidos y, en 1856, fue una de las seis mujeres graduadas en Medicina en la Facultad de Medicina Cleveland de la Western Reserve University, durante los cuatro años en que ésta estuvo abierta a las mujeres. Colaboró con Elizabeth Blackwell en la fundación del Hospital de Mujeres y Niños de Nueva York en 1857. En 1862, fundó el Hospital de Mujeres de Nueva Inglaterra. 
final de vuestros días como estudiantes, es realmente el comienzo de una educación superior" (Scharlieb, 1888, p.7).

Blackwell inicia la conferencia de comienzo de curso de la $L S M W$, en 1888, lamentando que todavía las mujeres no hayan alcanzado en Gran Bretaña las posibilidades de estudio ya existentes en EEUU, donde se contaba con más de 3.000 médicas. Pide a las alumnas que sean conscientes del alcance a largo plazo y los efectos sociales que supone el acceso de las mujeres a la profesión médica (Blackwell, 1890, p.2). Considera que deben preguntarse al inicio de sus estudios qué fin persiguen, puesto que, aunque sea lícito buscar el beneficio económico, éste no puede ser su único objetivo. La profesión médica está íntimamente ligada al progreso y el bienestar de la sociedad, no solo por el cuidado de la salud física, sino porque "el cuerpo y la mente están tan inseparablemente unidos en la constitución humana, que no podemos tratar con una parte de esta naturaleza compuesta, sin afectar a la otra, en mayor o menor grado" (Blackwell, 1890, p.4), de lo que deduce que la práctica médica tiene que estar guiada por un fin moral. Esta exposición de Blackwell muestra su visión de la misión moralizante de las médicas basada en lo que considera la "naturaleza" de la mujer: "el poder de la maternidad" (p.7) que implica "la subordinación del yo al bienestar de los demás" (p.8). Nada innovador, transgresor, ni en discordancia con el mandato de género vigente, evidentemente. Sin embargo, Blackwell conduce su discurso para afirmar que la esperanza de su época está en las mujeres y que no hay esfera, aparte del ámbito privado, donde éstas puedan ejercer mejor su misión que en el ejercicio de la práctica médica, siendo las áreas más adecuadas la medicina preventiva, la medicina general y la ginecología y resaltando las ventajas que la formación intelectual de las médicas representa para la sociedad. Tras recomendar la necesidad de observación y estudio detallado de la anatomía y la fisiología como requisitos para el aprendizaje, advierte de dos peligros para las estudiantes: la aceptación ciega de la autoridad y el materialismo que prevalece en muchos científicos. Como en otros escritos, encontramos aquí la posición de Blackwell, defensora del destino de la mujer como madre, y radicalmente influenciada por el pensamiento religioso, común a otras médicas que "apoyaban la visión esencialista de las cualidades especiales de las mujeres para ejercer la medicina, y consideraban que su área específica era la ginecológica y obstétrica, mientras otras, como Putnam, defendían que las doctoras tuviesen la más amplia formación posible y estuviesen presentes en diferentes campos de la medicina" (Iglesias, 2018b, p.113).

\section{ObRA de divUlgación: Fisiología, HIGIENE, EdUCACión SEXUAL.}

Dentro de la visión higienista de la época, las médicas pioneras realizaron también una labor de divulgación de conocimientos relativos al cuidado de la salud, la 
sexualidad, la alimentación, el vestido y la educación requerida por las mujeres para poder ocuparse de su propia salud y desempeñar sus funciones como madres.

Comenzamos con las tesis doctorales de Dolores Aleu, De la necesidad de encaminar por nueva senda la educación higiénico-moral de la mujer y Martina Castells, Educación física, moral e intelectual que debe darse a la mujer para que esta contribuya en grado máximo a la perfección y a la de la humanidad, se centran, como evidencian sus títulos, en su preocupación por rebatir los argumentos contra la educación de las mujeres y su acceso a la práctica médica profesional. No dejan de preconizar la maternidad como destino prioritario de las mujeres, con lo que no se enfrentan al discurso dominante, pero sí defienden la necesidad de la educación, incluso para cumplir mejor dicho destino.

Una educación que incluía lo físico, lo moral y lo intelectual, y que ponía un énfasis especial en el cuidado del cuerpo. La educación del cuerpo, objeto por parte de educadores, de médicos y de legisladores, más especialmente a partir de la segunda mitad de ese siglo XIX, demostró una finalidad que iba más allá del estudio y divulgación de la naturaleza masculina o femenina; en el caso de las mujeres, afectaba también a la función social, y hasta política, que se atribuía a la maternidad (Flecha, 2001, p. 223).

Castells defiende los beneficios de la educación, en concreto la médica, como profesional o como madre (dicotomía que seguían planteando algunas de las propias pioneras) con estas palabras:

Dad a la mujer representación en la sociedad; dejad que cultive su inteligencia y de este modo, contribuyendo a su felicidad, redundará el resultado en beneficio vuestro.

Si al final de su carrera, médica por ejemplo, una mujer se decide a ser esposa, sus conocimientos en vez de estorbarle le sirven en todos conceptos. ¡Ojalá todas las esposas y todas las madres pudiesen ser médicos! Si la mujer no se casa, produce un bien en la sociedad dedicándose a las enfermedades propias de su sexo; puede atender a ellas con solicitud por su carácter, sin distracción ninguna porque no la tiene, y tal vez proporcione a la ciencia algún nuevo conocimiento (Castells, 1882, cita tomada de Flecha, 2001, p.249).

Xavier Torredabella-Flix (2012), en su trabajo sobre las 35 tesis doctorales en Medicina presentadas entre 1853 y 1914 en relación con la educación física, menciona "cuatro que tratan consideraciones higiénicas de género y dieciséis tesis que tocan aspectos relativos a la educación física de la mujer" (p.59). Todas ellas redactadas por varones, ya que el autor no incluye las tesis de Aleu y Castells. Trece de estas tesis se encuadraban dentro del tema número 30: “Cuál es la educación física y moral de la mujer más conforme al gran destino que le ha confiado la divina Providencia?", de los 40 ofrecidos como temas para la disertación doctoral (Flecha, 2001, p.219). No 
era, pues, una temática innovadora, pero sí lo era el hecho de que fueran las propias mujeres, que habían tenido que sortear dificultades y obstáculos inexistentes para los hombres, quienes tomaran la palabra ante un tribunal examinador. Las tesis de Aleu y Castells se convierten así, no solo en el mero requisito de investigación para obtener el Doctorado, sino en un alegato en defensa del derecho a la educación superior y la práctica profesional de las mujeres que tanto les estaba costando conseguir en su propia vida. Así justifica Aleu esta elección temática en el comienzo de su disertación: "el considerar que aún hay quien discute y disputa a nuestro sexo la aptitud para los estudios profesionales, ha sido para mí motivo de inspiración para adoptar como objeto de esta tesis, el siguiente tema, que, si no tiene todo el mérito de la novedad, entrañará siempre los altos quilates de la oportunidad" (Aleu, 1883, p.2).

En 1880, Elizabeth Blackwell publicó The Human Element in sex. A consideration of facts in relation to the physical and mental organisation of men and women, addressed to students of medicine (El elemento humano en el sexo. Una consideración de hechos en relación con la organización física y mental de hombres y mujeres, dirigida a estudiantes de medicina $)^{36}$ , ejemplo de la visión de Elizabeth Blackwell sobre la sexualidad y la necesidad de educación sexual de los y las jóvenes, repetida en sus diferentes obras e intervenciones públicas. Blackwell aborda la relación entre la fisiología sexual y la moral cristiana, desde el planteamiento religioso y moralista predominante en toda su obra. Nada muy alejado de las posiciones oficiales, si tenemos en cuenta el título del tema de disertación doctoral a que acabamos de referirnos. Pese a que mantiene muchas de las afirmaciones, y errores, del discurso científico-médico de la época, realiza Blackwell algunas aportaciones interesantes. En primer lugar, reivindica la necesidad de que la moral se base en un conocimiento de la fisiología sexual, y denuncia que existe una laguna importante en la educación de la juventud, pues "en todos los excelentes tratados de fisiología, economía doméstica y educación, diseñados especialmente para la instrucción y ayuda de las madres, se omite todo conocimiento que se refiera a las funciones sexuales" (Blackwell, 1884, p.13). La educación sexual es necesaria para las y los jóvenes y resulta obligación de madres y padres. Los procesos fisiológicos, incluida la menstruación y las poluciones involuntarias (que Blackwell considera procesos similares, de expulsión del esperma y los óvulos no utilizados en la procreación) ${ }^{37}$, son naturales, lo que significa una interpretación normalizadora y positiva de la menstruación, opuesta a la visión de la misma como riesgo para la salud y proceso invalidante preconizado por muchos doctores, que contribuyen a rebatir el argumento del daño producido por la actividad intelectual en las jóvenes. “La devoción más alta

36 Las obras completas de Elizabeth Blackwell fueron recogidas en dos volúmenes, publicados en 1902, bajo el título de Essays in Medical Sociology (Ensayos en Sociología Médica), reeditados en 1972.

37 Recordemos que aún no se conocía el funcionamiento del ciclo menstrual. 
a la vida intelectual, a pensamientos elevados, a actos beneficiosos, jamás daña la capacidad de procreación" (Blackwell, 1884, p.30).

Defiende asimismo Blackwell una visión positiva del placer sexual: "No hay nada necesariamente malo en el placer físico. Aunque inferior en categoría al placer mental, es una parte legítima de nuestra naturaleza que lleva siempre consigo algún grado de acción mental" (p.19). Al igual que la satisfacción producida por otros sentidos, "el acto sexual en sí mismo debidamente entendido, está lejos de ser un mal necesario, es realmente una realización plena de las condiciones de nuestra vida presente totalmente justa y honesta, creada por la divinidad" (Blackwell, 1884, p.19). De acuerdo con su posicionamiento religioso, el placer sólo será aceptable cuando se ajuste a las normas morales que considera propias de una sociedad cristiana y se produzca dentro del matrimonio.

Aborda un tema no tratado generalmente por los doctores de la época: el placer sexual de la mujer, en el que considera tiene mayor papel que en el hombre el aspecto mental y espiritual. Reconoce Blackwell el hecho de que muchas mujeres encuentran más placer en los besos y caricias que en el coito, acto que "mentalmente les separa $y$ les es frecuentemente indiferente o repugnante" (p. 45). Apunta a posibles causas de este hecho, por la salud de la mujer o el comportamiento del esposo: “En la vida matrimonial, lesiones producidas en el parto, o un acercamiento conyugal brutal o inadecuado, pueden causar un alejamiento inevitable del acto sexual a menudo atribuido equivocadamente a falta de pasión" (Blackwell, 1884, p.45). Afirma que muchas mujeres sanas y enamoradas, que no han sufrido daños derivados del parto, pueden experimentar placer en el acto sexual.

Lo más importante a resaltar es que Blackwell, al igual que otras médicas y defensoras de derechos de las mujeres de la época, defiende la existencia de una única moral sexual para mujeres y hombres: recomienda la castidad, evitar la masturbación y reducir la frecuencia de realización del acto sexual, dado el desgaste físico que se suponía implicaba para el varón, pero las recomendaciones son similares para mujeres y hombres, sin conceder a estos el derecho a un ejercicio de la sexualidad negado a las mujeres. "Cualquier teoría que proponga dos métodos de juicio, o dos medidas legales, como consecuencia de una supuesta diferencia en la potencia vital es equivocada. El igual número de hombres y mujeres, su igual longevidad, y consecuentemente igual capacidad de soportar las dificultades de la vida, prueba el poder vital general igual en ambos sexos" (Blackwell, 1884, p.42). Por ello, afirma en el último capítulo que el instinto sexual existe igualmente en mujeres y hombres, pero que la castidad y la continencia no son instintivas en ninguno de los sexos y dependerán de la educación que considera en gran parte responsabilidad de los y las profesionales de la medicina. 
Rebecca Lee Crumpler publicó en 1883 A Book of Medical Discourses (Un libro de Discursos Médicos), obra de 145 páginas, “con unas pocas llamadas al sentido común dirigidas a madres, enfermeras y mujeres en general" (p.1). En 1896, Hanna Longshore publicó su obra de 351 páginas, Discourses to Women on Medical Subjects (Discursos a las Mujeres sobre Temas Médicos) "convencida la autora de la gran necesidad de las mujeres de instrucción fisiológica para evitar la gran cantidad de enfermedades que pueden afectarles" (Longshore, 1896, p.VII).

Aunque fue escrita por una educadora, incluiremos también en este apartado la obra Physiology and Calisthenics for Schools and Families, (Fisiología y Calistenia para Escuelas y Familias) de Catharine E. Beecher (1800-1878) ${ }^{38}$, publicada en 1858. Según la autora, “el objetivo del libro es enseñar métodos que pueden aplicarse para ayudar a que los niños y niñas se desarrollen con salud, fuerza, agilidad y buen aspecto" (p.9). Pretende también ser un manual de fisiología que pueda interesar a adolescentes, familias y profesorado. Una obra de divulgación, escrita en lenguaje sencillo, que incluye, tras el prefacio, 184 páginas con amplia información sobre anatomía y fisiología y recomendaciones para la salud, y otras 50 con ejercicios prácticos, ilustrados por figuras de niñas y niños, sin diferenciación por sexos en el tipo de ejercicios recomendados.

También algunas médicas rusas pronunciaron conferencias y publicaron libros divulgativos sobre la salud de las mujeres: Varvara Kasherova-Rudneva (1844-1899) ${ }^{39}$, publicó en 1892 Higiene para el organismo femenino en todas las fases de la vida. Elizabeth Drentel'n, titulada en los Curso de Medicina para Mujeres de San Petersburgo, accedió al Registro médico en 1883. Publicó varias obras: La salud de las mujeres: cuatro conferencias públicas. La necesaria dirección femenina de las instituciones sanitarias para mujeres y Sobre la prostitución (Den-Benste Barnett, 2001, pp.283-284). Mariia Volkova, también graduada en los Cursos para Mujeres de San Petersburgo publicó dos manuales con orientaciones de salud, uno dirigido a las mujeres y otro a los hombres.

Defendía la educación y el ejercicio físico para las mujeres, por lo que proponía una profunda reforma de la indumentaria femenina (Den-Benste Barnett, 2001, p.288).

\section{DECONSTRuCCIÓN DEL DISCURSO CIENTÍFICO-MÉDiCO DOMINANTE}

En Estados Unidos, en 1881, se realizaron dos investigaciones

38 Defensora del derecho a la educación de las mujeres. Fue profesora en una escuela de New Haven en 1821 y fundó un colegio femenino en Hartford (Conneticut) en 1823, donde impartió clases hasta 1832. Hermana de la escritora abolicionista de la esclavitud Harriet Beecher Stow, autora de Uncle Tom's Cabin (La cabaña del tío Tom).

39 Segunda mujer rusa graduada en Medicina en 1876 (la primera había sido Nadevna Suslova, graduada en Zúrich en 1867), y primera que obtuvo un permiso especial para realizar sus estudios y graduarse en Rusia, con la condición de dedicarse al cuidado de la salud de las mujeres que no podían ser atendidas por varones por motivos religiosos. Ejerció como médica en San Petersburgo. 
basadas en encuestas para definir los límites de las vidas profesionales de sus colegas y valorar sus progresos. Consideradas en conjunto, estas investigaciones demostraron los logros de las mujeres médicas a lo largo de medio siglo y pusieron de manifiesto su gradual integración con la profesión médica masculina. Al mismo tiempo, revelaron que continuaba vigente a lo largo del primer cuarto del siglo XX un separatismo que afectaba las carreras profesionales de las mujeres (Drachman, 1986, pp.59-60).

El estudio realizado por Rachel I. Bodley ${ }^{40}$ (1831-1888) fue impulsado por la Escuela de Medicina de Mujeres de Pensilvania de la que Bodley era Decana, y el de Emma Coll $^{41}$ y las hermanas Emily (1846-1930) y Augusta Pope (1846-1931) ${ }^{42}$, por el Nuevo Hospital para Mujeres y Niños de Nueva Inglaterra (New England Hospital for Women and Children). Estas obras, en vez de rebatir de forma teórica los argumentos contra el acceso de las mujeres a la medicina o tratar de avalar su empeño apelando a la historia, realizan un trabajo estadístico de investigación, mediante encuestas a mujeres médicas, en un momento en que comenzaban los estudios sociológicos sobre las mujeres.

A finales del siglo XIX y comienzos del XX, una generación de jóvenes mujeres en el campo de la ciencia social lideraron estas investigaciones. Su objetivo era poner a prueba la asunción de la sociedad victoriana estadounidense de que las mujeres eran diferentes de los hombres. Mediante la recogida sistemática y análisis de datos, examinaron las respuestas sexuales de las mujeres, sus capacidades intelectuales y físicas. Sus estudios proporcionaron evidencia factual, cuantificable, que contribuyó a refutar la creencia tradicional de las diferencias sexuales inherentes y a apoyar, por el contrario, la creciente aceptación de la igualdad entre los sexos (Drachman, 1986, pp.60-61).

Bodley analizó las carreras de 189 graduadas, mientras que el estudio de Emma Call y las hermanas Pope se extendió a 390 mujeres médicas de varias partes del país. Ambos estudios se basaron en cuestionarios sobre los siguientes temas: el tipo de práctica profesional desarrollado por las médicas; las especialidades a que se dedicaban; sus ingresos; su estado civil y su estado de salud. Los resultados mostraban que la mayoría se habían formado durante una media de poco más de cuatro años en algunas de las escuelas de medicina para mujeres de las ciudades de Nueva York, Boston o Filadelfia (áreas en las que residían); habían comenzado a practicar la medicina a los treinta y un años, como media. Llevaban en práctica activa durante unos diez años, relacionándose profesionalmente casi únicamente con mujeres, tanto colegas como pacientes. Se

40 Profesora del colegio universitario femenino Wesleyan Female Seminary desde su graduación en el mismo en 1849. Profesora de Ciencias Naturales del Colegio Femenino de Cincinnati. Profesora de Química y Toxicología en la Escuela de Medicina de Mujeres de Pensilvania y Decana de la misma desde 1874. Miembro de la Academia de Ciencias Naturales de Filadelfia y de la Academia de las Ciencias de Nueva York. Fundadora y primera mujer miembro de la Sociedad Química Americana de la ciudad de Nueva York.

41 Una de las primeras alumnas de la Escuela de Medicina de la Universidad de Michigan.

42 Graduadas por la Escuela de Medicina de Mujeres de Nueva Inglaterra. 
dedicaban a medicina general, obstétrica y ginecología en consultas particulares. Otras trabajaban en instituciones (hospitales, dispensarios, asilos y colegios) dedicadas a mujeres. Se sentían satisfechas con su profesión, sus ingresos y el trato dispensado por sus colegas masculinos, aunque casi dos tercios no pertenecían a ninguna asociación médica mixta. La mayoría permanecían solteras. Sólo 65 de las 390 del estudio de las hermanas Pope se habían casado tras graduarse, 19 de ellas con médicos. Catorce $(22 \%)$ habían abandonado la práctica profesional tras el matrimonio o al convertirse en madres, mientras que otras 21 (32\%) reconocían que las obligaciones domésticas interferían con sus vidas profesionales. Sin embargo, en el estudio de Bodley, casi la mitad de las encuestadas (47\%) se habían casado, siendo estudiantes, o tras graduarse. Y la mayoría reconocían haber conseguido un equilibrio entre su vida familiar y profesional. ${ }^{43}$

Lo más importante de estos estudios es que contribuyeron con las evidencias presentadas a

refutar el argumento de que la carrera médica era peligrosa para la salud de las mujeres. Esta creencia de que la práctica de la medicina constituía una seria amenaza a la salud de las mujeres se basaba en la noción del siglo XIX de la diferencia sexual. Mientras que se consideraba que los hombres eran naturalmente fuertes físicamente, las mujeres eran consideradas como inherentemente débiles (Drachman, 1986, p.63).

Las más importantes aportaciones, en este sentido, son las realizadas por Elizabeth Garrett y Mary Putnam Jacobi, al rebatir los argumentos misóginos expresados por los doctores Edward H. Clarke (1820-1877) ${ }^{44}$ y Henry Maudsley, (1835-1918) ${ }^{45}$. Clarke publicó en 1873 la obra titulada Sexo en la Educación o Una Oportunidad Justa para las Jóvenes (Sex in Education or A Fair Chance for Girls, 1873), basada en la conferencia pronunciada el año anterior en el Club de Mujeres de Nueva Inglaterra de Boston. En ella venía a afirmar que se deriva de la fisiología de la mujer la imposibilidad de

43 Las médicas pioneras no cuestionaban la creencia social imperante de que las responsabilidades domésticas (aunque fuesen realizadas a través de la supervisión del personal de servicio doméstico) y las derivadas de la maternidad eran responsabilidad de las mujeres, aunque ejerciesen asimismo una actividad profesional. Muy lejos aún de un enfoque feminista de corresponsabilidad en los cuidados.

44 Doctor en Medicina por la Universidad de Pensilvania. Ejerció como otorrino y médico generalista. Profesor de Farmacología de la Universidad de Harvard desde 1855 a 1872. Su obra tuvo amplia difusión en Estados Unidos y repercusión en otros países.

45 Neurólogo, superintendente del psiquiátrico de Manchester, coeditor del Journal of Mental Science, miembro del Real Colegio de Médicos, profesor de Jurisprudencia Médica de la Universidad de Londres, figura clave en el desarrollo de una teoría evolucionista de la mente, y defensor de la maternidad, que consideraba "inferior al noble oficio de hacer nacer ideas", como la función natural de la mujer. Maudsley publica las obras citadas en este trabajo en un periodo de reforma de la educación en Inglaterra y de lucha de las mujeres por el acceso al estudio de la medicina (Iglesias, 2012 y 2019). La influencia del pensamiento anglosajón en otros países, incluida España, hace relevante el análisis crítico de ambos autores. 
realizar los mismos estudios que los hombres y mantener al tiempo "un buen estado de salud y un futuro libre de neuralgia, enfermedad uterina, histeria y otros trastornos del sistema nervioso si sigue los mismos métodos que los muchachos" (Clarke, 1873, p.18). Se basaba en la extendida concepción de la menstruación como eliminación de residuos superfluos, por lo que se podrían provocar daños cerebrales si se producía amenorrea como consecuencia de dedicar las jóvenes al estudio la energía necesaria para sus funciones fisiológicas. Clark afirma no existir diferencia en la capacidad mental entre mujeres y hombres, pero sí en la forma de vida recomendable para cada sexo. Por ello,

si la joven dedica su energía a la actividad mental cuando la requiere para el desarrollo de su sistema reproductivo, éste quedará dañado para siempre, lo que apoya con algunos casos atendidos en su práctica médica y referencias a otros doctores, incluida la obra Cuerpo y Mente (Body and Mind, 1870) de Maudsley. Consecuentemente, desaconseja las escuelas mixtas y propone un sistema educativo para las chicas, con menor número de horas de estudio diarias y descansos de uno o varios días para cada alumna en la semana de su periodo menstrual, todo ello adaptado a lo que denomina el sistema periódico de las mujeres versus el sistema persistente de los hombres en el estudio y el trabajo (Iglesias, 2020, p.70).

Maudsley, a raíz del trabajo de Clarke, publicó en la Fortnightly Review de abril de 1874 un artículo titulado Sex in Mind and Education (Sexo en la Mente y la Educación), en el que criticaba a quienes defendían el derecho de las mujeres al acceso a la educación superior ignorando las diferencias entre los sexos. Insistía en cómo la energía dedicada al estudio afectará a la función reproductora, destino del que las mujeres no pueden escapar, aunque elijan no ser madres. La diferencia sexual afecta a la constitución y las capacidades cerebrales, ya que "hay sexo en el cerebro al igual que hay sexo en el cuerpo" (Maudsley, 1874, p. 469). Basándose en la repetida creencia de la íntima relación entre órganos reproductores y actividad mental, y los peligros de inhibición de la menstruación que la dedicación al estudio puede provocar en las jóvenes, propugna como Clarke "un sistema de educación adaptado a las mujeres que debería tener en cuenta las peculiaridades de su constitución, las especiales funciones a las que están destinadas en la vida, y el tipo y nivel de actividad práctica, mental y física, a la que deberían están sometidas por la organización sexual de su cuerpo y su mente" (Maudsley, 1874, p.483).

Elizabeth Garrett publicó un artículo rebatiendo los argumentos de Maudsley en el siguiente número de la misma revista, titulado Sex in Mind and Education: A Reply (Sexo en la Mente y la Educación: Una Respuesta). Garrett afirma que la mayoría de mujeres adultas continúa con su actividad normal durante el periodo menstrual, y llega a la conclusión de que "el número de mujeres en quienes los trastornos provocados por la menstruación interfieren seriamente con su actividad normal es muy reducido, siendo 
la norma general que la mayoría de mujeres sanas apenas experimenten, en ocasiones aisladas, un ligero malestar" (Iglesias, 2020, p.75). Señala, incluso la mayor capacidad creativa e intelectual experimentada por algunas mujeres durante la menstruación (Garrett, 1874, p.585). Defiende que las condiciones de higiene, trabajo intelectual y actividad física serán sin duda más beneficiosas para la salud corporal y mental de las jóvenes que la falta de motivación a que pueden verse abocadas por la reclusión y la vida monótona y superficial a que la sociedad las condena. $Y$, por último, resalta también que el esfuerzo que pueda suponer para las jóvenes acceder al mismo sistema de estudio que los chicos, no tiene sus raíces en la fisiología femenina, sino en que las mujeres tienen que enfrentar dificultades que no existen para los varones:

Hasta aquí, la mayoría de las mujeres que han «competido con los hombres para obtener sus mismas ambiciones» no han tenido la posibilidad de fallar por hacerlo en igualdad de condiciones. Han gozado del beneficio de contar con unas dificultades extra, inexistentes para los hombres. Además de su supuesta inferioridad física y mental, han tenido que comenzar la carrera sin gran parte del entrenamiento de que los hombres han disfrutado, o bien, lo han conseguido por sus propios medios, una atmósfera de hostilidad, que les ha supuesto mucha más fuerza y capacidad de resistencia que el trabajo intelectual más exigente (Garrett, 1874, p.589).

También los argumentos de Edward Clarke fueron rebatidos en 1874, en varios libros escritos por mujeres: Woman's Education and Woman's Health: Chiefly in Reply to "Sex in Education" (La Educación y la Salud de la Mujer: Fundamentalmente en Respuesta a "El Sexo en la Educación"), de Anna Manning y Georges Comfort, en el que critican a Clarke por generalizar, sin realizar estudios comparativos de salud entre mujeres con y sin estudios. Y dos antologías: Sex and Education. A Reply to Dr. E. H. Clarke's "Sex in Education" (Sexo y Educación. Una Respuesta a "Sexo en la Educación" del Dr. E.H. Clarke), compuesto por 13 artículos y cinco textos sobre los colegios Vassar, Antioch, Oberlin y las universidades de Michigan y Lombard, editada por Julia Ward (1819$1910)^{46}$ autora de la introducción y el primer capítulo. Ward critica la falta de estilo e imparcialidad científica de la obra de Clark, que tampoco podría considerarse una obra filosófica o moral, por lo que la califica como "una obra polémica, que presenta un alegato persistente y apasionado contra la admisión de mujeres a la educación superior junto con los hombres" (Ward, 1874, p.14).

La otra antología, La Educación de las Jóvenes Americanas Considerada en una serie de Ensayos (The Education of American Girls Considered in a Series of Essays), editada por Anna Callender Brackett (1836-1911) ${ }^{47}$, consiste en catorce ensayos de diferentes

46 Escritora, sufragista y abolicionista. Primera mujer elegida para la Academia Estadounidense de las Artes y las Letras.

47 Profesora y traductora, graduada por la Escuela de Pedagogía de Framinghan (Massachusetts). En 1875, fundó la Escuela Brackett para Chicas de Nueva York. 
autoras, entre ellos el trabajo de 51 páginas de la doctora Mary Putnam, Mental Action and Physical Health (Acción Mental y Salud Física), en el que reforzaba con argumentos basados en la anatomía y la fisiología las consideraciones morales del resto de los artículos.

Putnam acusa a Clarke de no probar empíricamente sus afirmaciones, exagerando la incapacidad de las jóvenes durante la menstruación y atribuyendo falsamente los trastornos de amenorrea y menorragia a la actividad intelectual. Reconoce la profunda interrelación entre mente y cuerpo (Putnam, 1874, p.259), pero critica que se apele una y otra vez a lo largo de la historia a las funciones fisiológicas femeninas para justificar "todas las teorías sobre la naturaleza de las mujeres, es decir, todas las teorías de la organización de la sociedad" (Putnam, 1874, p.260). Refuerza sus argumentos con los datos obtenidos en el estudio realizado por ella con 20 mujeres de entre 18 y 30 años, ofreciendo información sobre aquellas entrevistadas que habían sufrido algún trastorno relacionado con la menstruación (Putnam, 1874, p.264), para concluir que la proporción es de aproximadamente una sexta parte, y que en ningún caso el periodo de molestias sobrepasa las 48 horas (Putnam, 1874, p.265). Atribuye las causas de los problemas de hemorragia o amenorrea a la vida sedentaria; a situaciones de intenso trastorno emocional (Putnam, 1874, p.267); a enfermedades tales como anemia, reumatismo o malaria, y a predisposición hereditaria. Para rebatir la repetida teoría de la imposibilidad de realizar bien las funciones intelectuales y fisiológicas, realiza una detallada explicación descriptiva del sistema nervioso humano, concluyendo que si fuera cierta la completa subordinación del cerebro a los instintos en la mujer,

quizás la hubieran reducido inconscientemente al nivel anatómico de los crustáceos; así, quienes como el Dr. Clarke insisten en la incompatibilidad entre la acción cerebral y la actividad refleja en las mujeres, las convierten en seres inferiores fisiológicamente a los animales o individuos en que tal incompatibilidad no existe (Putnam. 1874, p.273).

Dedica más de cuatro páginas a la posible interrelación entre excitación de las emociones, trastornos del sistema nervioso y trabajo intelectual, detallando la diferencia entre los efectos corporales del cansancio provocado por el estudio y el provocado por una profunda emoción (Putnam, 1874, p.291). Concluye que la inferioridad intelectual de las mujeres depende de la cultura y condiciones de vida y no del tamaño craneal (Putnam, 1874, p.300), por lo que es recomendable la educación intelectual completa para chicas y chicos, extendida durante un periodo amplio de años, que incluya ejercicio físico y entre cuatro y seis horas diarias de trabajo intelectual (Putnam, 1874, p.301), educación que debería ser mixta durante la infancia, separada por sexos durante la adolescencia "por razones morales" (Putnam, 1874, p.304), pero "a partir de los dieciocho años las razones contra la coeducación de los sexos han dejado de existir, 
y entran en juego razones imperativas a su favor" (Putnam 1874, p.305), lo que implica permitir el acceso de las mujeres a las universidades en igualdad con los varones.

El estudio más conocido de Mary Putnam en relación con la supuesta incapacitación de la mujer durante el periodo menstrual es el ensayo titulado The Question of Rest for Women During Menstruation (La Cuestión del Descanso para las Mujeres durante la Menstruación), elaborado con motivo de la convocatoria en 1876 del premio anual Boylston, de la Facultad de Medicina de Harvard, sobre la temática ¿Necesitan las mujeres descanso físico y mental durante la menstruación, y en qué medida? La elección de esta cuestión se debía a que algunos doctores de la Facultad eran conscientes de la baja calidad del trabajo de Clarke y consideraban conveniente contar con otras contribuciones científicas. Animada por otras defensoras de derechos de las mujeres de Boston, Putnam presentó su trabajo, de forma anónima según las normas, y firmado con el seudónimo Vertías poemate verior. Tras ser premiado por el comité, compuesto por profesores de la Facultad, el estudio de Putnam fue publicado al año siguiente en un volumen de 282 páginas. La autora modificaba la visión invalidante de la menstruación y contribuía a derribar las barreras argumentales contra la admisión de las mujeres en la universidad.

Dicha obra consistía en una investigación realizada a partir de los datos recogidos medianteun cuestionario de 16 preguntas, respondido por 268 participantes de diferente formación académica y distintas ocupaciones, incluidas profesoras, médicas, obreras y trabajadoras del servicio doméstico. De las 268 participantes, el 35\% no habían sufrido nunca dolores menstruales. Del 65\% restante, dos tercios tenían problemas de tipo genético o enfermedades que les provocaban debilidad y trastornos ginecológicos. Respecto a la necesidad de descanso durante el periodo menstrual, Putnam deducía de los datos obtenidos que la falta de trastornos menstruales se basaba en: una infancia sana; una historia familiar libre de trastornos; la realización de ejercicio durante la vida escolar; la amplitud y extensión de la educación intelectual; el mantenimiento de buena salud general y ejercicio físico tras la etapa escolar; tener una ocupación estable y casarse a una edad adecuada (Putnam 1877, p.62). Y concluía que "no existe nada en la naturaleza de la menstruación que implique que sea necesario, ni siquiera deseable, el descanso para aquellas mujeres cuya nutrición es realmente normal" (Putnam 1877, p.227). El reposo era únicamente recomendable en aquellos casos de dolor agudo o cuando las mujeres debían realizar trabajos extremadamente duros, mientras que en el resto de casos podría resultar incluso contraproducente. Por el contrario, coincidía con Garrett en que para algunas mujeres el periodo menstrual representaba un incremento de vitalidad y energía mental (Putnam, 1877, p.109).

Putnam rechazaba la teoría que asociaba ovulación, calor y excitación sexual, por lo que reconceptualizó la menstruación en las hembras humanas como un proceso ligado 
a la nutrición, o a un aspecto de ésta, el reproductivo, en vez de a un proceso sexual (Putnam, 1877, pp.166-67), cuestionando la creencia de la época de la simultaneidad entre ovulación y menstruación, que se derivaba de la observación del periodo de celo en las perras.

Mary Putnam continuó posteriormente investigando sobre la menstruación y las enfermedades ginecológicas, y a partir de mediados de los años ochenta se implicó asimismo en la investigación neurológica, apoyando el beneficio de la actividad física e intelectual para la salud de las mujeres. "Al rechazar un abordaje de la diferencia sexual como oposición, se centró en los aspectos físicos comunes entre el cuerpo masculino y el femenino, creando un modelo biológico que permitía soportar un modelo social basado en roles de género simétricos" (Bittel, 2009, p.227). Una importante aportación científica para desmontar la justificación de la desigualdad preconizada desde el discurso científico-médico dominante.

Mencionemos finalmente Physiology of Woman (La Fisiología de la Mujer) (1880), de Sarah Hackett Stevenson (1841-1909) ${ }^{48}$. Se trata de una obra de 230 páginas, que incluye un capítulo de 28 páginas sobre "Coeducation of the Sexes in Medicine" ("Coeducación de los Sexos en la Medicina") y cuyo objetivo, según la autora, es proporcionar información a las mujeres sobre su fisiología, rebatiendo la visión de la invalidez femenina

En lo que se refiere a los muchos libros sobre temas similares, no hay ninguno, que yo sepa, de ninguna autoridad que no enseñe que la naturaleza hizo que las mujeres sean inválidas. De ahí la necesidad de un libro más. Éste no es un libro de medicina. La medicina no es, y nunca puede serlo, una ciencia popular. Me opongo a la automedicación de todo tipo. El médico ${ }^{49}$ que ofrece prescripciones al público se coloca por encima del nivel de quien pone una patente médica en el mercado. Mi objetivo es la falsa información que las mujeres han recibido. Si cualquiera de mis hermanos médicos son culpables de fomentar así la credulidad de las personas ignorantes, de ellos espero la censura. Por otra parte, creo que ningún verdadero médico puede poner objeciones a la información que estas páginas pretenden impartir. (Stevenson, 1874, p.2)

Stevenson (1874) basa en la naturaleza el derecho de las mujeres a la educación, por poseer un órgano que permite la actividad intelectual, es decir el cerebro, que en modo alguno es inferior al del varón por tener menor tamaño, en contra de los planteamientos de la craneología (p.146). Las mujeres, por tanto, tienen derecho a estudiar en las mejores condiciones posibles. Es también natural que hombres y mujeres estudien

48 Graduada en Medicina por la Escuela de Medicina del Hospital de Mujeres (Woman's Hospital Medical College) de Chicago en 1874, en la que fue profesora de fisiología e histología desde 1875 a 1880 y de obstétrica desde 1880 a 1894. Fue la primera mujer admitida en la American Medical Association (AMA) (Asociación Médica Americana) en 1876. Junto con otras pioneras fundó la Illinois Training School for Nurses (Escuela de Formación de Enfermeras de Illinois) en 1880.

49 En la versión original la autora utiliza el término "physician" que no tiene marca de género y puede referirse a médicas y médicos. Sin embargo, sí utiliza el término "brethen" (hermanos). 
juntos ya que "fueron creados el uno para el otro, en todas las relaciones de la vida" (Stevenson, 1874, p.152).

En el apartado dedicado a la menstruación, Stevenson rebate también la supuesta debilidad provocada por la misma en las mujeres, coincidiendo con Garrett y Putnam, autora a la que menciona directamente, al afirmar que "una buena observación de las mujeres sanas prueba que los días que preceden la menstruación son días de mayor capacidad" (Stevenson, 1874, p.38).

\section{ObRAS DE INVESTIGACión CIENTÍFICA}

Numerosas pioneras de la medicina, produjeron obras de carácter científico, como los artículos de Dolores Aleu, publicados durante su etapa de estudiante: Escrofúlide ulcerada grave generalizada (1877) y Caso clínico de artritis reumática (1878) o los numerosos artículos publicados por médicas rusas en la revista médica nacional Vrach.

Destacamos, por su calidad científica, la obra de Mary Putnam Jacobi, entre otros, su estudio sobre el útero y los ovarios, recogido en una colección de artículos titulados Studies in Endometritis (Estudios sobre la Endometriosis), publicados en el American Journal of Obstetrics and Diseases of Women and Children (Revista Americana de Obstetricia y Enfermedades de las Mujeres y los Niños) en 1885. Putnam “examinó el útero y los ovarios a nivel celular para contrastar el crecimiento y expulsión normal de la menstruación con la inflamación patológica. Mediante el examen al microscopio de tejido uterino y ovarios enfermos extraídos de pacientes, produjo imágenes de tejidos enfermos y sanos" (Bittel, 2009, p.229), tratando de encontrar las causas en los casos de inflamación patológica. Este trabajo vino a completar el iniciado sobre la menstruación en 1874. Muchos doctores apoyaron sus teorías fisiológicas, incorporaron sus métodos de investigación y reprodujeron sus resultados. "Por ejemplo, muchos médicos estuvieron de acuerdo con su crítica a la teoría de la ovulación, sobre todo cuando comenzaron a cuestionar la simultaneidad entre menstruación y ovulación" (Bittel, 2009, p.228).

Citemos asimismo su trabajo titulado Essays on Hysteria, Brain Tumour and some other cases of nervous disease (Ensayos sobre la Histeria, el Tumor Cerebral y otros casos de enfermedad nerviosa), publicado en 1888. Dada la amplia literatura producida por varones médicos sobre la histeria como trastorno propiamente femenino, derivado del mal funcionamiento de los órganos reproductivos de las mujeres, el trabajo de Putnam resulta especialmente interesante, al investigar sobre las causas de la histeria, sus manifestaciones y los posibles tratamientos. Basándose en estudios neurológicos, atribuyó la histeria a deficiencias fisiológicas y nutricionales derivadas en gran parte de las limitaciones impuestas en la vida de las mujeres; rechazó la imposición del 
descanso y la inactividad como terapia adecuada, considerando que muchas mujeres necesitaban más bien estímulos para librarse de los síntomas histéricos. Rebatía de nuevo los argumentos de una figura de referencia en Estados Unidos, el médico Silas Weir Mitchell (1829-1914), experto en histeria y promotor de la denominada "cura de reposo", magníficamente descrita de manera crítica por Charlotte Perkins Gillman, escritora y reformista feminista, en su relato The Yellow Wall Paper (El papel de pared amarillo) publicado en 1892, a partir de su propia experiencia de dicho tratamiento en 1887.

\section{LAS MÉdicAS COMO PROTAGONISTAS DE OBRAS LITERARIAS}

El impacto social de las reivindicaciones de las mujeres médicas se refleja en su presencia como protagonistas de algunas obras literarias.

En 1884, la escritora estadounidense Sarah Orne Jewtt publicó A country doctor (Una médica rural), que narra la historia y nacimiento de la vocación de la joven Nan Prince, que seguirá los pasos de su tutor, el doctor Leslie, médico rural.

Charles Reade (1814-1880) publicó A Woman Hater (Un Hombre que odia a las Mujeres), por entregas en el Blackwoods's Magazine entre junio de 1876 y junio de 1877 y posteriormente como novela en tres volúmenes. La infancia de la protagonista, Rhoda Gale, está inspirada en la infancia de Elizabeth Blackwell, y sus dificultades en el acceso al estudio de la medicina recogen los hechos reales sucedidos en la Universidad de Edimburgo, de los que Charles Reade tenía conocimiento directamente por Sophia Jex-Blake.

En 1886, Henry James incluyó el personaje de una médica, la doctora Mary J. Prance en su obra The Bostonians (Las Bostonianas) y en 1892, Margaret Todd (1859-1918) ${ }^{50}$, publicó la novela de 474 páginas, Mona Maclean, Medical student, a novel, (Mona Maclean, estudiante de Medicina, una novela) bajo el seudónimo de Graham Travers, siendo esta la única de las obras citadas escrita por una médica. Al año siguiente, Sophia JexBlake publicó un artículo sobre las médicas en la ficción (Medical Women in Fiction) en que alaba la obra de su alumna y compañera, Margaret Todd.

Nan Prince, protagonista de A Country Doctor, elige la dedicación a la medicina como una llamada personal que implica renunciar al matrimonio. Rhoda Gale, también afirma que ama la ciencia como otras mujeres aman a los hombres, lo que puede recordar la elección personal de pioneras como Elizabeth Blackwell o Jex-Blake. Sin embargo, Mona Maclean da un paso adelante en el derecho de la mujer a realizar

50 Estudió Medicina en la Escuela de Medicina de Mujeres de Edimburgo fundada por Sophia Jex-Blake, donde ejercicio como profesora durante cinco años. Obtuvo el Doctorado en Medicina en Bruselas en 1894. Publicó varias obras. Fue la autora de la primera biografía de Jex-Blake, The Life of Sophia Jex-Blake (La vida de Sophia Jex-Blake), publicada en 1918. 
ambos aspectos de su vida, al igual que lo haría un varón. Combina su vocación profesional y su relación personal, casándose con un hombre con el que comparte también la dedicación a la medicina. En este sentido, Margaret Todd presenta un modelo de mujer médica que estaría más cercano a la vida real de Elizabeth Garrett, Mary Putnam y otras pioneras.

\section{ConcLusiones}

Para las mujeres, tomar la palabra ha sido (y aún es en ciertos ámbitos y lugares) un acto transgresor. Para las mujeres que tuvieron que superar grandísimas dificultades para acceder a la educación superior y el ejercicio profesional de la medicina, tomar la palabra, a través de conferencias y publicaciones, fue una forma más de contribuir al avance en la consecución de ese derecho. Con sus obras, médicas como Sophia Jex-Blake, Edith A. Huntley, Mélanie Lipinska y más tarde Kate Campbell HurdMead, comenzaron la construcción de la historiografía de las mujeres en el cuidado de la salud; Jex-Blake, Edith Huntley, Francis Hoggan, Elizabeth Blackwell, Elizabeth Garrett, Isabel Thorne, Mary Scharlieb o Franciska Tiburtius, contribuyeron a escribir la historia del propio movimiento del que eran protagonistas, proporcionando testimonios y datos muy relevantes para investigaciones posteriores. Pioneras como Florence Nightingale, Garrett, Blackwell, Marie Zakrzewska o Mary Scharlieb crearon materiales y pronunciaron conferencias destinadas a la formación de las futuras médicas y enfermeras. Las médicas pioneras rebatieron los argumentos contra el acceso de las mujeres al estudio y práctica de la medicina con estudios como los realizados por Mary Putnam, Rachel I. Bodley, Emma Coll y las hermanas Emily y Agusta Pope. Muy especialmente, cabe destacar los trabajos de Elizabeth Garrett y Mary Putnam Jacobi, que contribuyeron a despatologizar las funciones fisiológicas de las mujeres ofreciendo una visión positiva de las mismas. Blackwell y Putnam, desde distintas posiciones, plantearon argumentos científicos contra la doble moral sexual para hombres y mujeres, dando así unos primeros pasos hacia la deconstrucción de la política sexual patriarcal. Algunas pioneras de la medicina moderna realizaron también importantes aportaciones al conocimiento científico de su época, abriendo el camino de la investigación y la construcción de conocimiento para las siguientes generaciones de médicas y científicas, destacando también en este sentido la actividad de Mary Putnam como investigadora. Asimismo, médicas de diferentes países publicaron obras divulgativas sobre fisiología y cuidado de la salud, destacando las aportaciones de Elizabeth Blackwell, Sarah Hackett Stevenson, Varvara Kasherova-Rudneva, Elizabeth Drentel'n, o Mariia Volkova, y las tesis doctorales de las dos pioneras de la medicina moderna en España, Dolores Aleu y Martina Castells. Podemos, por tanto, concluir que las pioneras de la medicina moderna, a través de su propia vida y de sus obras, 
contribuyeron a deconstruir la misoginia del discurso científico-médico sobre la salud, la sexualidad y el cuerpo de las mujeres que ofrecía argumentos para mantener la situación de discriminación de las mujeres en la sociedad, su limitación al ámbito privado y su destino único e irrenunciable a la función de esposa y madre. Y aportaron una conceptualización más equilibrada y positiva de la fisiología femenina basada en el conocimiento científico y los estudios estadísticos.

\section{BIBLIOGRAFÍA}

Aleu Riera, Dolores (1877). Escrofúlide ulcerada grave generalizada. La Independencia Médica, 9, 93-96.

--- (1878) Caso clínico de artritis reumática. La Independencia Médica, 9, 1878, 266-270.

--- (1883). De la necesidad de encaminar por nueva senda la educación higiénico-moral de la mujer. Barcelona: Tipografía “La Academia" de Evaristo Ullastres.

Beecher, Catharine E. (1858). Physiology and Calisthenics for Schools and Families. Harper \& Brothers.

Bittel, Carla (2009). Mary Putnam Jacobi and the Politics of Medicine in Nineteenth-Century America. University of North Carolina Press.

Blackwell, Elizabeth. (1874). The human element in sex: A medical enquiry into the relation of sexual physiology to Christian morality. J.\&A. Churchill. 3ㅜ. ed. 1884.

--- (1895). Pioneer work in opening the medical profession to women. Longmans, Green and Co.

--- (1902). Essays in Medical Sociology. Vols. I \& II. Arno Press \& The New York Times.

Bodley, Rachel L. (1881). The College story: Valedictory Address to the Twenty-Sixth Graduating Class of the Woman's Medical College of Pennsylvania. Grant, Aires and Rodgers.

Bonner, Thomas Neville (1992). To the ends of the Earth. Women's Search for Education in Medicine. Harvard University Press.

Calvo, Yadira (2016). La aritmética del patriarcado. Barcelona: Edicions Bellaterra.

Crawford, Elizabeth (2002). Enterprising women. The Garretts and their circle. Londres: Francis Boutle Publishers.

Den-Benste Barnett, Michelle (2001). Publica o perece: las publicaciones científicas de las médicas en la Rusia imperial. En Cabré, Montserrat y Ortiz, Teresa (eds.) Sanadoras, matronas y médicas en Europa. Siglos XII-XX. (pp.277-301). Barcelona: Icaria.

Drachman, Virginia G. (1986). The limits of progress: The professional lives of women doctors, 1881-1926. Bulletin of History of Medicine, 1986 (1), 58-72. 
Finkelstein, David. (1995). A woman hater and Women healers: John Blackwood, Charles Reade and the Victorian Women's Medical Movement. Victorian Periodicals Review, 28 (4), 330-352.

Flecha García, Consuelo (1996). Las primeras universitarias en España 1872-1910. Narcea.

--- (2001). La educación de la mujer según las primeras Doctoras en Medicina de la Universidad española, año 1882. En Cabré, Montserrat y Ortiz, Teresa (eds.) Sanadoras, matronas y médicas en Europa. Siglos XII-XX. (pp. 217-250). Barcelona: Icaria.

--- (2019). Barreras ante las pioneras universitarias: Una mirada transnacional. CIAN. Revista de Historia de las Universidades, 22, 20-59.

Flecha García, Consuelo y Palerno, Alicia Itatí. (2019). Women in the universities. Strategies and achievements of a secular presence in Latin America and Spain. Culture and History, 8 (1).

García Dauder, Silvia y Pérez Sedeño, Eulalia (2017). Las "mentiras" científicas sobre las mujeres. Madrid: La Catarata

Garrett Anderson, Elizabeth (1874). Sex in Mind and Education: a reply. The Fortnightly Review (15), 582-594.

--- (1893). The History of a Movement. Fortnightly Review, 404-417.

Hoggan, Francis (1843-1927). Women in Medicine. En Stanton, Theodore (ed.). The Woman question in Europe. (pp.63-89). Putnam's Sons.

Huntley, Edith A. (1886). The Study and Practice of Medicine by Women. Farncombre \& Co. Lewes.

Iglesias Aparicio, Pilar (2012). Mujer y Salud. Las Escuelas de Medicina de Mujeres de Londres y Edimburgo. Tesis doctoral. Editorial Académica Española

--- (2018a). Estrategias utilizadas por las pioneras de la medicina moderna en América y Europa. En Manuel Alcántara, Mercedes García Montero y Francisco Sánchez López (coord.). Estudios de Género. Memoria del 56º Congreso Internacional de Americanistas, (pp.230-238). DOI: http://dx.doi.org/10.14201/0AQ0251_9

--- (2018b). Cuatro pioneras de la medicina moderna: Elizabeth Garrett, Sophia JexBlake, Mary Scharlieb y Mary Putnam Jacobi. En Yolanda Romano Martín, Sara Velázquez García y Mattia Bianchi (coord.), La Mujer en la Historia de la Universidad: Retos, Compromisos y Logros, (pp.103-115). Ediciones Universidad de Salamanca.

--- (2019) Las Escuelas de Medicina de Mujeres de Nueva York y Londres. Estrategia de las pioneras para el acceso al estudio y práctica de la Medicina. CIAN. Revista de Historia de las Universidades, 22, 61-86. 
--- (2020). Contribución de las mujeres a la deconstrucción de la misoginia del discurso científico-médico del siglo XIX. Filanderas. Revista interdisciplinar de estudios feministas, 5, 63-80. https://papiro.unizar.es/ojs/index.php/filanderas/index

Jex-Blake, Sophia (1872). Medical Women. A thesis and a history. Vol I: Medicine as a Profession for Women. Vol.II: The Medical Education of Women: 1. The Battle in Edinburgh, 2. The Victory Won. (2 $2^{\mathrm{a}}$. ed. 1886, Oliphant, Anderson and Ferrier).

--- (1875). The practice of medicine by women. Fortnightly Review, 392-407

--- (1887) Jex-Blake, Sophia. Medical women. The Nineteenth Century, noviembre de 1887, 692-707

--- (1893). Medical women in fiction. The Nineteenth Century, febrero de 1893, 261-272. Jewett, Sarah Orne (1884). A country doctor. Houghton, Mifflin \& Co.

Lipinska, Mélanie (1900). Histoire des femmes médecins depuis l'Antiquité jusqu'à nos jours. Librairie G. Jacques.

--- (1930). Les femmes et le progrèss des sciences médicales. Masson.

Maudsley, Henry (1874). Sex in Mind and Education. The Fortnightly Review, 15, 466483.

Meyer, Paulette (2001). La práctica sin licencia en la clínica de médicas de Berlín: La trayectoria profesional de Franziska Tiburtius (1843-1927). En Cabré, Montserrat y Ortiz, Teresa (eds.) Sanadoras, matronas y médicas en Europa. Siglos XII-XX. (pp.251276). Icaria.

Moscucci, Ornella (1990). The Science of Woman. Gynaecology and Gender in England 1800-1929. Cambridge: CUP

Nightingale, Florence (1859). Notes on Nursing. What it is and what it is not. Harrison. (2ª ed. 1860) Appleton and Company.

Ortiz, Teresa (1999). De matrona a matrona: Francisca Iracheta y la divulgación de la ciencia obstétrica en España en 1870. Arenal. Revista de historia de las Mujeres, 183193.

--- (2018). [2006] Medicina, historia y género. 130 años de investigación feminista. Oviedo: KRK (Segunda edición).

Pope, Emily F; Call, Emma y Pope, Augusta (1881). The Practice of Medicine by Women in the United States. Wright and Potter.

Putnam Jacobi, Mary (1874). Mental Action and Physical Health. En Callender Brackett, Anna, The Education of American Girls Considered in a Series of Essays, (pp.255-306). Nueva York: Putnam's Sons.

--- (1877). The question of rest for women during menstruation. The Boylston Prize Essay of Harvard University for 1876. Nueva York: Putnam's Sons. 
--- (1882a). Shall Women Practice Medicine? The North American Review, 134 (302), 5275.

--- (1885) Studies in Endometritis. American Journal of Obstetrics and Diseases of Women and Children.

--- (1888) Hysteria. Brain-tumor and some other cases of nervous disease. Nueva York: Putnam's Sons.

Reade, Charles (1814-1880) (1877). A Woman Hater. Blackwood.

Russett, Cynthia Eagle (1995) [1989]. Sexual science. The Victorian Construction of Womanhood. Cambridge: Harvard University Press. (4. ${ }^{a}$ edic. 1995).

Scharlieb, Mary (1888). Seven Lamps of Medicine. Horace Hart. --- (1898). Women in the medical profession. Women's Institute.

Swenson, Kristine (2005). Medical women and Victorian fiction. University of Missouri.

Thorne, Isabel (1905). Sketch of the Foundation and development of the London School of Medicine for Women. G. Sharrow.

Todd, Margaret (1892). Mona Maclean, Medical Student. A novel. Blackwood.

Torredabella-Flix, Xavier (2012). Las primeras tesis doctorales sobre educación física en el espacio científico y profesional de la medicina española (1853-1914). Pecia Complutense, 9 (6), 58-88.

Theriot, Nancy M. (1993). Women's Voices in Nineteenth-Century Medical Discourse: A Step toward Deconstructing Science. Signs (19/1), 1-31.

Tuana, Nancy (1993). The Less Noble Sex. Scientific, Religious and Philosophical Conceptions of Woman's Nature. Indianópolis: Indiana University Press

Tracy, Martha (1881). Women graduates in medicine. Bulletin of the American Association of Medical Colleges.

Wells, Susan (2001). Out of the Dead House: Women Physicians and the Writing of Medicine. University of Wisconsin. 